\title{
EL OJO PENSANTE
}

Luis Argudín

INSTTUUTO dE INVESTIGaciones FiLOSÓFICAS

Universidad Nacional Autónoma de México

\section{Introducción}

La preocupación central de este trabajo es la imaginación y, más específicamente, la imaginación dirigida a las artes visuales; la relación que la imaginación tiene con la percepción normal del mundo y con la contemplación de obras artísticas. Según el pintor Paul Klee, ${ }^{1}$ el ojo que aprecia una pintura piensa a través de las formas, los colores, las líneas y las figuras que percibe. Su pensamiento no es conceptual ni abstracto, está totalmente encarnado en la materia que recrea y transforma. Pero si la visión estética es pensante, no es el único ejemplo de visión interpretativa; tenemos, por ejemplo, el caso de reconocer a una persona a la distancia o el que Wittgenstein llamó "ver aspectos", que consiste en ver algo como si fuera otra cosa (ver el follaje de un árbol como un perfil). En todas estas situaciones se da una muy clara fusión de pensamiento y visión o de pensamiento perceptual, combinación que tradicionalmente ha caracterizado a la imaginación.

El trabajo está dividido en tres secciones. La primera se encarga de la discusión sobre el tema de la imaginación en la percepción y del reconocimiento perceptual. La segunda introduce el concepto de "ver aspectos" como el ejemplo perfecto de la comunión del ver y el pensar. Por último, la tercera parte se concentra en las características gráficas que promueven o inhiben la transición entre la imagen visual y el concepto al que refieren.

El intento de mayor importancia encaminado a diferenciar entre visión estética y cotidiana se lo debemos a Kant. Puesto que quiere darle a la estética un dominio autónomo, independiente de la ética y del conocimien-

1 Paul Klee, The Thinking Eye, Faber \& Faber, Londres, 1972. 
to, procede a definir el Juicio de Gusto (o acto de contemplar lo bello) en contra del Juicio Cognoscitivo (o acto de conocer el mundo mediante el uso de conceptos). Así, la contemplación estética se enfrenta al conocimiento (perceptual e intelectual) del mundo, a veces de una manera, drástica, como cuando excluye lo conceptual del juicio de gusto puro, y otras de forma más atenuada, como en la antinomia del gusto, donde acepta que el juicio de gusto sí requiere de un concepto, aunque éste debe ser indeterminado. La confrontación puede resumirse de la siguiente manera: tanto la visión estética como la cognoscitiva requieren de las mismas facultades sensoriales y conceptuales (o en términos kantianos, imaginación y entendimiento), pero una se distingue porque su fin es el placer producido por el libre juego entre sensaciones y conceptos, mientras que la otra exige que de su interrelación se pase de lo sensorial a una conclusión conceptual.

Al contemplar estéticamente, lo importante es el placer que produce el juego y la interrelación entre formas y sentido, líneas y representación; la visión cognoscitiva, por el contrario, centra su atención no en el proceso, sino en la conclusión, esto es, en la fijación conceptual. Cuando tratamos de reconocer a alguien entre la multitud de la calle, lo que nos importa es que las conjeturas que formamos sobre las caras indistintas en la lejanía se resuelvan en la cara que buscamos. Si sentimos placer no es porque probemos una variedad de soluciones; sólo lo sentimos cuando acertamos al identificar a la persona esperada. Se ha hablado frecuentemente de la similitud que existe entre el placer estético y el placer de resolver un problema matemático, un acertijo o un crucigrama. La diferencia, sin embargo, no deja de ser notable: el placer que sentimos en matemáticas se produce cuando resolvemos el problema y no en el proceso mediante el cual llegamos a la solución. Esto es lo contrario del placer estético, el cual proviene del intento, puesto que no hay una solución concluyente y definitiva.

Para Kant, la distinción entre visión estética y cotidiana reside en la resolución o irresolución que se le da a lo sensorial mediante la acción fijadora de los conceptos. He aquí el meollo del problema: la relación que tiene la visión con el pensamiento conceptual. Pero el ojo pensante de Klee no es el ojo que ve más la mente que piensa; es el ojo inteligente que piensa a través de lo que ve. La inteligencia del ojo no se origina en el pensamiento abstracto, sino en Ia organización formal de lo visible; no es intelectual, sino imaginativa. Por esta razón, tanto Kant como Hume afirmaron que la imaginación juega un papel activo en la percepción, aparte del que desempeña en las actividades creativas como el arte.

El ejemplo típico de la función que desempeña la imaginación dentro de la percepción es el reconocimiento perceptual. Reconocemos a un 
objeto que apenas se delínea en la distancia; a un amigo que no veíamos en mucho tiempo o que nos encontramos en la oscuridad de un cine; reconocemos una planta entre la hierba del jardín o a un familiar entre una multitud. Yo no reconozco a mi esposa cada vez que la veo, aunque la reconocería rápidamente entre un grupo de personas; pero si la espero en la calle y llega tarde a la cita, es muy probable que me equivoque y que crea verla cuando lo que en verdad veo es a un extraño. Mi visión se tiñe de expectativas y al huscar a mi esposa proyecto las características que la distinguen sobre las figuras que veo, comparo los rasgos que conozco con las figuras que veo. En ciertas ocasiones, sin embargo, sucede que creo reconocer a mi eposa y me dirijo hacia ella hasta que de cerca descubro mi error; estaba interpretando lo que veía y la interpretación resultó ser errónea. Mi visión y lo que conozco de ella actuaban conjuntamente, y lo noto, precisamente, porque el error deja al descubierto el carácter activo de la percepción, probando hipótesis visuales sobre formas. todavia conceptualmente indeterminadas. Pero en sentido estricto no estaba yo interpretando lo que veía; el hecho es que describo como una "interpretación", que puede ser acertada o errónea (como todo significado semántico), mi experiencia perceptual que, en tanto estado mental, no puede calificársele como verdadera o falsa. En el momento en que las circunstancias me permiten reconocerla sin lugar a dudas como mi esposa se produce la fijación conceptual de la percepción, con lo cual se termina la fase activa de la visión.

Cásós como éste parecen confirmar ìa afirmación kantiana de que la imaginación está activa en la percepción, pero que sólo aflora al nivel consciente cuando el esfuerzo que implica tratar de reconocer a alguien en condiciones adversas lo trae al centro de nuestrá atención. Las asociaciones, permutaciones y comparaciones que caracterizan a la imaginación dentro de la sensibilidad la hacen el candidato ideal para explicar la visión interpretativa.

Pero como lo vio Kant, la capacidad asociativa de la imaginación no basta para explicar el sentido que tiene el mundo percibido. Por más que asociemos imágenes varias de algo, éstas nunca se resolverán en un objeto por la mera fuerza del hábito o la costumbre (como dice Hume), si carecen de la relación con un concepto que les dé la unidad de sentido que necesitan. Sólo la visión, conjuntamente con la capacidad conceptual de la mente, puede darle orden a lo perceptible. Reconocer a una persona entre la multitud implica el activo ordenamiento de lo visible de acuerdo con las especificaciones de un concepto. Pero, si por un lado el reconocimiento perceptual parece acercarse a la actividad imaginativa, por otro se distingue y se separa de ésta. El reconocer a una persona se opone a la actitud imaginativa porque su fin no es el libre juego de 
proyecciones, sino la solución del estado de indeterminación mediante la fijación conceptual de lo percibido. Es la reacción equivocada que podemos tener cuando visitamos un museo: el que únicamente se dedica a reconocer el autor y la escuela a la que pertenece cada cuadro, no ve las cualidades formales que son el resultado de una visión prolongada o contemplación; como cualquier filisteo, pasa de la experiencia visual al reconocimiento conceptual del objeto.

Ahora bien, la función que la imaginación desarrolla dentro de la percepción es una manera de explicar la continuidad que existe entre el pensamiento abstracto y las sensaciones, continuidad que con frecuencia, y salvo en el campo de lo estético, se ha tomado como una oposición lógica. ${ }^{2}$ El papel de la imaginación dentro de la percepción puede entenderse de dos maneras distintas. 1) Por una parte, podemos pensar que la imaginación, en tanto facultad que comparte características de estado pasional y de acto volitivo, es la mediadora entre dos opuestos: pensamiento y percepción. ${ }^{3} \mathrm{Si}$ tomamos este punto de vista, adjudicaremos a la imaginación el activo ordenamiento de lo perceptible y, consecuentemente, achacaremos a la sensibilidad un estado de pasividad análogo a la película fotosensible de una cámara fotográfica que registra "impresiones". Éste es un error fácil de cometer porque es el resultado de antecedentes filosóficos, principalmente de corte racionalista, que han tomado la diferencia entre pensamiento y percepción como una oposición lógica.

2) Pero también podemos entender la función imaginativa de la per-

2 La razón, creo, se remonta a la concepción griega de la verdad que, al ser accesible únicamente mediante conceptos universales, se contrapone a la percepción de lo aparente, lo sensible y lo particular. Según Platón, contemplamos las formas ideales con el intelecto y la apariencia con los sentidos. La fusión de la forma intelectual y la experiencia sensible en un solo acto no se da salvo en una excepción: Ia forma de lo bello. La belleza es lo único que, inmerso en lo aparente y expuesto a la percepción relativa de los sentidos, nos deja entrever el reino de las formas absolutas. Todo lo que percibimos adolece de la relatividad que impone un punto de vista desde un lugar y a un tiempo determinados. Un objeto bello, en cambio, aunque es percibido por los sentidos parece trascenderlos pues ejerce una atracción sobre nosotros que, mediante el "eros", nos mueve a superar el punto de vista particular. Por eso lo bello es para Platón, así como después sería para Hegel, la encarnación de la verdad de las formas ideales en el mundo de la apariencia sensible. Desde entonces, intelecto y percepción se oponen, si no en la experiencia, sí lógicamente, como lo verdadero frente a lo falso e ilusorio.

3 Eva Schaper, Studies in Kant's Aesthetics, Edimburgh University Press, 1979. E1 articulo relevante es el primero, "Imagination and Knowledge", donde Schaper sostiene la tesis de que Kant parece caer en la tentación de usar la facultad de imaginar como puente entre las sensaciones y los conceptos, especialmente en la primera edición de la Critica de la Razón Pura, en la Estética Trascendental; posición que cambia en la segunda edición. Lo que nos importa aqui no es lo que haya pensado Kant, sino mostrar lo fácil que es considerar a la imaginación de esta forma. 
cepción, más humildemente, no como el producto de una facultad puente que une dos contrarios, sino como ejemplo de una clase de experiencias que con toda naturalidad mezclan la visión con el pensamiento. La imaginación dejaría así de ser un caso atípico de la fusión de dos experiencias contrastantes, si concebimos una unidad entre todos los actos y sensaciones que forman parte de la conciencia.

John Dewey, por ejempio, presenta un modelo de la mente donde la conciencia es el resultado de la irrupción de factores inesperados que exigen reacciones improvisadas y novedosas. Adquiere carácter consciente aquella respuesta que rompe con los mecanismos automáticos que nos permiten funcionar sin gastar mayor energia que la mínima necesaria. A un nivel inconsciente operamos todo lo que por el hábito podemos controlar. Al manejar un vehículo automáticamente metemos el clutch al mismo tiempo que cambiamos las velocidades, frenamos cuando inesperadamente se detiene el automóvil de enfrente, calculamos si el nuestro cabe en medio de dos autos estacionados, etc. Cuando estamos aprendiendo, somos conscientes del esfuerzo que nos cuesta llevar a cabo todas estas acciones, pero una vez que adquirimos confianza al manejar, esto desaparece de nuestra mente para podernos ocupar del camino.

De hecho, la conciencia de lo que percibimos proviene del esfuerzo que ejercemos para seleccionar, excluir, completar y estabilizar situaciones que se nos presentan como un obstáculo o reto, ya sea por desconocidas, por salirse de lo común y trillado, o porque rompen con los procedimientos de respuesta a los cuales la mente está habituada. La conciencia surge donde termina el hábito. Todo lo habitual, lo automático, lo conocido se ve cubierto por un manto de inconsciencia, mientras que lo consciente impone un comportamiento que trasciende la reacción habitual. Según Dewey:

...wherever perceptual awareness occurs there is a moment of hesitation; there are scruples, reservations, incomplete overt action. ${ }^{4}$

Nace la conciencia cuando un estímulo produce una ruptura en los habituales mecanismos de respuesta y dudamos sobre cómo calificar la experiencia; nos vemos forzados a detenernos para probar distintas interpretaciones hasta encontrar la adecuada. En otras palabras, estamos ante una situación que pide una reacción creativa y exige un esfuerzo consciente de nuestra parte. Pero si esto es un rasgo distintivo de todo lo consciente, lo es, sobre todo, de las experiencias imaginativas.

No hablamos de la imaginación cuando podemos actuar de acuerdo

4 John Dewey, Experience and Nature, Dover, Nueva York, 1958, especialmente el capitulo: "Nature, Mind and Subject." 
con mecanismos inconscientes guiados por el hábito o la costumbre, sino cuando esta forma de actuar no es suficiente para enfrentar adecuadamente una circunstancia novedosa. Usamos la imaginación porque tenemos que encontrar una manera alternativa de actuar. No imaginamos lo que se presenta claramente a nuestros sentidos, pues para esto basta la percepción guiada por la experiencia pasada. Imaginamos, en cambio, lo que no tenemos enfrente, lo que no existe pero podría existir o quisiéramos que existiese; lo que confusamente vemos debido a la falta de visibilidad, a la distancia, etc.; lo que, aun viéndolo claramente, desconocemos: ignorando cómo clasificarlo, probamos diversas maneras de asimilarlo dentro del conjunto de nuestras experiencias pasadas. No imaginamos lo que vemos: no vemos un tenedor como si fuera un tenedor; es un tenedor y no nos preocupamos más por ello (P. I., p. 195e). ${ }^{5}$ En cambio, sí imaginamos que algo que vemos puede ser un objeto totalmente distinto del que es; imaginamos el tenedor como una mano metálica, como una arma, etc. La imaginación implica visualización, pensar algo y darle un contenido empírico sensible, hacerlo visible, o ver algo y pensarlo de manera distinta a la usual. Es la reunión del ver con el pensar.

Al sacar una conclusión de la discusión anterior, podemos decir que, según la posición 1), vista arriba, la imaginación está activa en la percepción porque a) se acepta que la percepción es un estado pasivo de registro de sensaciones, y $b$ ) se concentra el aspecto activo de la percepción en la imaginación en detrimento de la percepción. Aceptando esto sólo podremos explicarnos los casos donde la percepción activamente interpreta su contenido sensorial (como en el reconocimiento perceptual) recurriendo a la facultad de imaginar. $\mathrm{Y}$ de ahí fácilmente se sigue que si la imaginación actúa en los casos en que estamos conscientes de ello, también lo hará aun cuando no seamos conscientes de su acción. La imaginación extiende así sus funciones de acto creativo y renovador, hasta abarcar la función de síntesis (ya sea trascendental, como dice Kant, o meramente empírica) de las sensaciones, forzando con ello el significado original del concepto. Pero si, por el contrario, tomamos la posición 2), podremos dar sentido a los ejemplos de visión interpretativa, de otra forma problemáticos, sin tener que recurrir a una facultad productora de imágenes activa de manera misteriosa, esto es, inconsciente, en la percepción.

La dificultad estriba en suponer que la imaginación puede ejercerse de una forma inconsciente. Aceptar esto significa no diferenciar entre imaginación, que, como vimos arriba, es el producto de un esfuerzo voli-

5 Ludwig Wittgenstein, Philosophical Investigations, Basil Blackwell, Oxford, 1974. Desde ahora: 'P.I.' 
tivo (que es el fundamento de la conciencia), y fantasia, que es la pura y autónoma asociación de palabras e imágenes en el permanente fluir de la mente. La intuición, a la que brevemente nos referimos antes, no es imaginativa; depende más bien de la fantasía, si bien, como afirma Kant en relación con la imaginación "productiva" y "reproductiva", están en permanente contacto. La creatividad imaginativa es el resultado de un esfuerzo de la voluntad, pero asimismo se alimenta de procesos inconscientes. La imaginación se beneficia del influjo del inconsciente porque, a diferencia del pensamiento conceptual, mantiene un estado abierto de "juego", indecisión o irresolución que permite la entrada de las asociaciones libres y automáticas, que tanto fascinaron a André Breton. ${ }^{6} \mathrm{O}$ como lo hubieran expresado los pensadores románticos que primero se interesaron por el tema: la actividad creativa de la imaginación se produce por la unión de la inspiración, característica involuntaria del genio, y el intelecto, que modula, canaliza y tiempla las ideas que recibe del primero.

Creativa por excelencia, la imaginación se alimenta de mecanismos inconscientes sin por ello perder el control consciente. Ésta es la primera razón que nos conduce a rechazar la idea de que la imaginación necesariamente consciente tenga una función inconsciente en la percepción. La segunda es que la imaginación y la percepción normalmente se contraponen en la experiencia: la primera implica la ruptura o discontinuidad del funcionamiento de la segunda. La percepción normal cognoscitiva de las cosas no puede ni debe detenerse en la contemplación detallada del objeto. La visión no puede ser estática porque nuestro cuerpo y nuestros ojos están en perpetuo movimiento. No debe posarse más de lo necesario en la contemplación del objeto, ya que hacerlo significa excluir de nuestro campo de visión todo excepto la cosa contemplada. Sólo vemos durante el tiempo necesario para poder reconocer la clase de objetos que tenemos enfrente; esto es, vemos no por el mero gusto de ver (lo que caracteriza la visión imaginativa), sino para poder utilizar, consumir, evitar, comprender, reconocer y transformar el objeto percibido. Ante el ver contemplativo, el ver por el gusto de ver, se yergue el ver para, cuyo fin es recoger información sensorial para la superviven-

6 Friedrich Schiller, Aesthetic Education of Mankind, O.U.P., Oxford, 1972; de la sección de comentarios de Wilkerson y Willoughby: "Parece no ser bueno y perjudicial para el funcionamiento creativo de la psyche, si el entendimiento somete a un escrutinio demasiado severo el torrente de ideas casi, por decirlo asi, en la misma entrada. Una idea que consideramos aisladamente podrá parecer sin importancia o muy extravagante; pero quizás gane en relevancia por otra que inmediatamente le siga; y quizás en una cierta conjunción con otras ideas, que en sí mismas parecen no menos insípidas, resulte ser un eslabón valioso (en la cadena de la imaginación); el entendimiento no puede juzgar nada de esto, a menos que lo mantenga el tiempo suficiente para verlo en conjunción con estas ideas" (p. 293, mi traducción). 
cia de la criatura. La imaginación se alimenta de la irresolución perceptual que permite probar distintas interpretaciones hasta hallar la más adecuada; la percepción depende, en cambio, del conjunto de soluciones previas que marcan los parámetros para clasificar el objeto visual. Como sostenía Hume, la percepción es creencia, ya que sería no sólo impráctico, sino contraproducente para los fines que persigue la percepción, que nos cuestionáramos todo lo que vemos; mientras que la imaginación es duda, pues se nutre de lo inestable e indefinido, de lo incompleto y desconocido. Sobre estos rasgos que alimentan la imaginación tratará la próxima sección.

\section{II}

En la sección anterior discutimos el tema de la imaginación en la percepción. Ahora quiero centrar la atención en casos específicos donde se revela y resalta la acción de la imaginación. Los ejemplos y los temas que de ellos se originan los tomamos de las Investigaciones filosóficas de Wittgenstein. El rasgo más sobresaliente de la imaginación es el de compartir características de la sensación, como la vivacidad e intensidad de la imagen, su sensorialidad, etc., y del pensamiento, como estar sujeta a la voluntad y ser modificable por un cambio de opinión. ${ }^{7}$ Wittgenstein describe el concepto de "ver aspectos" (seeing as), concepto análogo al de la imaginación, como la fusión de pensamiento y sensación: "Hence the flashing of an aspect on us seems half visual experience, half thought." (P. I., p. 197e). "The echo of a thought in sight." (P. I., p. 212e). "Is being struck looking plus thinking?" (P. I., p. 211e).

El concepto de "ver aspectos" ilustra el punto intermedio entre la percepción y el pensamiento; de ahí que Wittgenstein afirme que es un concepto modificado de la percepción, distinto porque se aleja de ésta para acercarse al pensamiento. "Seeing as. .' is not a part of perception. And for that reason it is like seeing and again not like." (P. I., p. 197e). Pero la razón de mayor peso por la cual la experiencia de ver aspectos se distingue de la percepción es la indeterminación conceptual que exige como condición necesaria; un requisito similar es el que impone Kant para el juicio estético, pues debe permitir el libre juego de sensaciones y conceptos gracias a la presencia de conceptos indeterminados, según dice la antinomía del gusto (sección 57 de la Crítica del Juicio).

Cuando percibimos, los objetos están definidos, fijados conceptualmente. Las cosas y las personas adquieren sentido gracias a una red o es-

7 Estas características se enumeran en Roger Scruton, Art and Imagination, Routledge and Kegan Paul, Londres, 1982, p. 109. 
tructura de significado con la cual establecemos el orden, la forma y la secuencia de lo que vemos. El sentido y la función de los objetos, como descubrieron los surrealistas, depende del contexto en el cual se encuentran. Si los transportamos a un medio que les sea ajeno su significado variará, y por lo tanto la manera en la que organicemos su apariencia física. El paraguas en un quirófano de Dalí es diferente al paraguas que tenemos en casa; el urinal de Duchamp es otro que los que encontramos en los baños públicos. Lo mismo que sucede con los objetos pasa con las palabras. Éstas adquieren sentido mediante el uso que se les da dentro de una unidad lingǘstica (ya sea una frase o una oración), por lo cual la falta de dicha estructura provocará una indeterminación en el significado de la palabra. Si oímos la palabra "casa" sin escuchar el sentido que le da la oración, ésta podrá referirse al hogar, a una cacería, a un casamiento, a la relación de dos objetos, etc. ${ }^{8}$ Podemos pensar la palabra, ahora en un sentido, después en otro, y cambiar de sentidos alternativamente según encajemos la palabra dentro de uno u otro contexto que imaginemos.

La falta de contexto, asi como una débil, deficiente o trastocada presentación de lo percibido, es necesaria para que se dé la indeterminación conceptual requerida para ver aspectos. Ya hemos visto que a la distancia yo creo ver a mi esposa en gente que, de estar cerca, nunca tendría para mí ningún parecido con ella. Pasemos ahora a los ejemplos que Wittgenstein mismo da. Estos pueden dividirse, en términos generales, en tres clases.

1) La primera abarca figuras donde hay sólo dos opciones que notar, ya sea la figura o el fondo, como positivo o negativo: la figura de Jastrow, mejor conocida como el pato-conejo, el cubo Necker (que puede dar la apariencia de ser visto desde arriba o desde abajo), etc. En estos casos es clara la falta de definición de la figura con relación al fondo, gracias a la cual podemos, alternativamente, centrar nuestra atención en uno u otro. La figura del pato-conejo se fijaría en un conejo si afianzáramos los rasgos de este animal agregándole bigotes y dibujándole la boca, o viceversa. En todos estos ejemplos el cambio de un aspecto al otro se debe a la coexistencia de dos posibles lecturas de igual peso, de tal forma que tenemos tanta evidencia para verlos según uno como según el otro aspecto.

2) El caso que hemos utilizado de reconocimiento perceptual caería dentro de la segunda clase de ejemplos usados por Wittgenstein, con la

8 "But there is the phenomenon that when a word is heard outside any context - for example - for a fleeting moment it has one meaning, and the next moment another" (Wittgenstein, Remarks on the Philosophy of Psychology, Basil Blackwell, Oxford, 1980, pp. 34, 167). 
salvedad de que al reconocer a una persona a la distancia se da una fijación conceptual y hay criterios para poder decidir el acierto o equivoco de nuestra interpretación, cosa que no sucede con los ejemplos de ver aspectos, donde no hay una lectura definitiva o correcta. Los ejemplos de este inciso difieren del primero en dos maneras. a) Al ver la figura de Jastrow, si vemos el aspecto conejo no podremos simultáneamente ver el aspecto pato, e igualmente sucede con los otros ejemplos de figura y fondo, con el cubo, etc. Aquí la ambigüedad genera una total oposición psicológica entre las dos lecturas, de manera que una excluye necesariamente a la otra. El cambio entre ver un aspecto y ver el otro es virtualmente mecánico, como el de un switch eléctrico; hay un movimiento retinal cuando, al ver el pato (donde nos concentramos en el pico), saltamos a verlo como conejo (donde el énfasis se encuentra en el ojo y la boca). En los ejemplos del tipo 2), por lo contrario, no hay contradicción entre dos lecturas excluyentes: cuando me encuentro a Juan, un viejo amigo que hace tiempo que no veo, lo que veo es la cara del Juan de antes en la cara del Juan de ahora ("I see the old face in the altered one"). (P. I., p. 197e). b) Pero cuando reconozco el rostro que conocía de Juan y lo comparo con el de ahora, lo que veo no está en la cara de mi amigo, mientras que tanto el pato como el conejo sí están en la figura de Jastrow. Lo que veo en la cara de Juan es algo que yo proyecto sobre ella y que exije un esfuerzo imaginativo de mi parte para notar el parecido entre la apariencia que ahora tiene y la que yo le conocí hace tiempo. Los ejemplos del inciso 2), donde encontramos el parecido entre dos objetos, dos caras, dos animales, etc., sí requieren de la imaginación para notar el aspecto, lo cual no es necesario para los del inciso 1). La diferencia consiste en que el salto entre ver el pato y ver el conejo es casi mecánico, un movimiento retinal que no da espacio para nada más que el paso de uno a otro aspecto. Al notar un parecido, el aspecto no proviene de un movimiento ocular sino de la visualización de unas facciones a partir de un rostro que vagamente se le asemeja.

3) La tercera clase de ejemplos se distingue por la variedad de lecturas posibles. Cualquier figura aislada, geométrica o irregular, siempre y cuando no sea la representación reconocible de un objeto que nos remite a un concepto, puede ser vista según un número ilimitado de interpretaciones. Podemos ver un triángulo agudo como la punta de un iceberg, la parte superior de un sombrero, la vela de un barco, el techo de una iglesia, etc., pero para verlo, digamos como el pico de una iglesia, necesito visualizar los detalles que completen el esquemático dibujo triangular y recrearlo en mi imaginación como el techo de una iglesia gótica irguiéndose contra el cielo.

Lo específico de la experiencia de ver aspectos es el salto que damos 
de ver una misma figura según un aspecto a verla de acuerdo con otro modo de organización. El ejemplo que tipifica esta característica central a este concepto es la figura de Jastrow (o cualquier ejemplo del inciso 1), pues permite únicamente dos lecturas. Aquí no se necesita la imaginación (que ampliaría las opciones innecesariamente) ya que su función es enfatizar la experiencia del cambio de un aspecto al otro. El salto de ver la figura como pato a verla como conejo, ilustra lo que Wittgeinstein llama "the dawning of an aspect (P. I., p. 212e), o bien, "being struck by an aspect" (P. I., p. 212e). Si vemos la figura como un pato sin transformarla en la apariencia de un conejo no estaremos viendo aspectos; solamente si cambiamos de una lectura a otra se presentará la indeterminación conceptual que separa el ver aspectos del simple ver. Esto se debe a que al ver aspectos evitamos la fijación conceptual centrando nuestra atención, no sólo en lo que vemos, sino en lo que no vemos ("-but what I perceive in the dawning of an aspect is not a property of the object, but an internal relation between it and other objects" (P. I., p. 212e)). El efecto de esto es una reorganización de lo percibido; los aspectos son maneras alternativas de estructurar lo que vemos, "aspects of organization" (P. I., p. 208e), variaciones de la imaginación a lo perceptualmente dado.

En resumen, los ejemplos que cita Wittgenstein para ilustrar el concepto de ver aspectos tienen algo en común: todos son imágenes generalizadas, altamente abstractas, que ni definen ni especifican, en tanto representaciones, su objeto, y tampoco, en tanto imágenes libres (geométricas o irregulares), el contexto dentro del cual se deben ver. Como vimos, las figuras ambiguas, así como las libres del inciso 3), dejan de serlo si les agregamos el detalle que fija el sentido y el contexto de la representación. La figura de Jastrow se convierte en conejo si le dibujamos bigotes y boca, el triángulo agudo se torna torre gótica completando la iglesia debajo de él. La primera conclusión que podemos sacar es que la falta de especificidad de la imagen crea una incertidumbre sobre la lectura apropiada que estimula la proyección de dos o más maneras de ver la representación. La segunda conclusión es que las figuras usadas como ejemplos, al ser formas generalizadas, facilitan la transición de la imagen a la idea, aunque en algunos casos no estemos seguros o haya ambigüedad sobre a qué idea se refieren. Al ser dibujos esquemáticos, no sostienen la observación prolongada, sino que nos llevan directamente de la experiencia visual a la idea conceptual. Por eso sentimos ante el dibujo de un círculo con tres hayas horizontales y una vertical en el medio partir

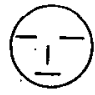
que no vemos una cara; más bien pensamos una cara a del dibujo que vemos. Llamamos por tanto a esto una interpretación, lo cual no haríamos si el dibujo fuera de Rubens o 
Ingres. ${ }^{9} \mathrm{El}$ ver aspectos es un híbrido de ver y pensar gracias a las características formales de ciertas imágenes y a la respuesta que éstas suscitan en nosotros. Por ello, en la próxima sección, veremos la manera en que distintas clases de imágenes provocan respuestas diversas.

\section{III}

Desde Platón hasta Kant se había especulado sobre las formas paradigmáticas de la belleza. Para el primero eran las figuras geométricas perfectas que reflejan en la apariencia sensible una armonía interna espiritual por parte del sujeto que las traza.y del espectador que las contempla; para el segundo eran las figuras libres, carentes de un orden fácilmente asimilable que, por su complejidad y detalle, suscitan el examen visual. El criterio de belleza que usa Platón es todavía un concepto ético de perfección mientras que Kant ya utiliza un criterio estético moderno: lo bello es lo que soporta y mantiene el escrutinio de nuestra visión. Wittgenstein no menciona la belleza en las Investigaciones filosóficas, pero sí se refiere a una característica que, siendo esencial al concepto de "ver aspectos", ilumina un rasgo distintivo de la experiencia estética: la indeterminación conceptual. Esto no quiere decir que el arte necesite de la ambigüiedad o falta de definición propia de los ejemplos usados para ilustrar el concepto de "ver aspectos"; más bien significa que, al igual que en el ver aspectos, en el arte se evita o limita (aunque por distintos medios) la fijación conceptual, para así permitir el libre juego de la visión estética, esto es, el ver por el gusto mismo de ver. En esta última sección del trabajo veremos cómo las características formales de una configuración y el uso social que le damos facilitan o dificultan el interés estético por el objeto.

Creo que dos comentarios que hace Wittgenstein con relación a la experiencia de ver aspectos son fundamentales para entender el papel que juegan las imágenes en nuestra vida.

l) El primero es:

Here it is difficult to see that what is at issue is the fixing of concepts. A concept forces itself on one. (This is what you must not forget.) (P. I., p. 204e.)

9 John Dewey, Art as Experience, Capricorn Books, Nueva York, 1958: " $A$ person with a knack can jot down lines that suggest fear, rage, amusement ...But the result is not an object of perception. What is seen passes at once over into the thing suggested. The drawing is similar in kind though no in its constituents to a signboard. The object indicates rather than contains meaning" (p. $90 \mathrm{~s}$.). 
2) El segundo es:

The substratum of this experience is the mastery of a technique. (P. I., p. 208e.)

En la cita 1) Wittgeinstein nos recuerda que la importancia del concepto de "ver aspectos" reside en hacernos plenamente conscientes de que al percibir algo simultáneamente se nos impone el concepto que define el objeto. Esto lo logra gracias al salto que damos al ver una cosa, primero bajo un aspecto y luego bajo otro. Al cambiar de aspecto una misma configuración, sentimos, cual si viéramos dos objetos y se nos impusieran dos distintos conceptos, dos clases marcadamente distintas de organización formal. Cuando vemos la representación de un pato después de ver la de un conejo, dos conceptos luchan por fijarse sin conseguirlo, porque la evidencia visual no favorece a uno sobre el otro. El ver aspectos enfoca y resalta el proceso de fijación conceptual en el percibir mediante una experiencia (rara, por lo demás, en situaciones normales) donde es imposible llegar a una decisión sobre el concepto apropiado. En conclusión, podemos decir que toda imagen o representación impone un concepto, el cual a su vez define la clase de organización formal del objeto y la respuesta que suscita.

En la cita 2), Wittgenstein afirma que para poder tener la experiencia de ver aspectos es preciso estar familiarizado no sólo con los conceptos a los que refieren las representaciones, sino también con la técnica gráfica usada en las imágenes. Sería imposible notar aspectos en la figura de Jastrow si desconocemos la apariencia de patos y conejos, o de cubos, triángulos, etc., en los otros ejemplos, pero, asimismo, no podríamos cambiar de un aspecto a otro o ver el cubo desde abajo o desde arriba si no conocemos las técnicas de representación pictórica y el dibujo de perspectiva. Si esto es cierto de la experiencia de ver aspectos, también lo es de las representaciones gráficas. Como afirman Gombrich y Goodman, toda representación, y en última instancia todo arte, tiene como fundamento un cuerpo de técnicas y procesos convencionalmente aceptados que forman un código compartido por cierto grupo de personas, lo cual hace posible la comunicación del sentido deseado. En palabras de Gombrich:

Todo arte se origina en la mente humana, en nuestras reacciones frente al mundo más que en el mundo mismo, y precisamente porque todo arte es "conceptual", todas las representaciones se reconocen por su estilo. ${ }^{10}$

10 E. H. Gombrich, Arte e Ilusión, Gustavo Gili, Barcelona, 1979, p. 89. 
En resumen, de la cita 1) se puede desprender que toda representación impone un concepto que determina el modo de organización y la respuesta apropiada hacia la imagen; y de la cita 2), que toda representación es el producto de un conjunto de conceptos y técnicas compartidas por una sociedad. La imagen impone un concepto porque es producida con una intención dentro de una tradición y un contexto social. Pero si bien toda representación es conceptual, en el sentido en que comunica un contenido (como lo hace cualquier letrero de tránsito), hay que distinguir entre aquel tipo de representaciones que facilitan y aquellas que desalientan la transición entre la configuración y el concepto. A las que la facilitan las llamaremos, siguiendo a Gombrich en Arte $e$ Ilusión, imágenes conceptuales, y las que la inhiben, imágenes visuales.

A las imágenes o representaciones conceptuales se les aplica este adjetivo porque son la representación visual de un concepto o pensamiento, a media distancia entre el signo, cuya relación con su objeto es puramente convencional y no depende ya del apoyo visual (las letras del vocabulario), y la representación figurativa realista, cuya liga con el objeto es (o parece ser) de similitud. Por ejemplo, el plano de un avión para armar no fue hecho para contemplarse estéticamente, pero tampoco es equiparable a unas instrucciones carentes de apoyo visual. Su función es distinta tanto de los signos lingüísticos como de las pinturas artísticas, dado que su fin es ayudarnos a visualizar aquello que queremos entender. Si bien la visión está involucrada, lo primordial es la comunicación de la información que contienen.

Todo plano, mapa o diagrama de un objeto, o cualquier dibujo esquemático, así como la pintura infantil y el mal llamado arte primitivo, caen dentro de esta categoría. En todos ellos el sentido es ajeno o externo a la configuración, por lo que dependen de un código o explicación para hacernos entender el mensaje que comunican. Por ello su función no es exclusivamente visual; son más bien el complemento visible de un pensamiento: lo que comunican no se da únicamente a través de lo que representan. En su apariencia formal son imágenes bidimensionales, planas, que enfocan ciertas cualidades del objeto que representan en detrimento de otras que no le interesan al productor. La pintura infantil y primitiva (al igual que los mapas, planos, etc.) son idiosincráticos; todo tiene un sentido y una explicación, pero éste es el que le da el artista: él escoge qué retratar y qué excluir, la importancia que les da a ciertas características sobre otras mediante el tamaño, el colorido, la posición central, etc., de ahí que la apariencia final de la representación obedezca más a sus inclinaciones y gustos personales que a las cualidades propias del objeto retratado.

Las representaciones visuales, por lo contrario, buscan un ideal de 
objetividad e imparcialidad, tanto en la visión como en la reproducción de lo que vemos, que el crítico inglés del siglo pasado, John Ruskin, calificó como el "ojo inocente". El ojo del artista debe ser inocente cuando está frente al objeto, para poder verlo como si fuera la primera vez y asi apreciarlo, aun siendo algo cotidiano, como insólito e interesante. El ojo inocente no sólo anhela desembarazarse de los prejuicios e inclinaciones que nos hacen preferir algo sobre lo otro por razones extrínsecas a la apariencia del objeto; también busca una visión fresca capaz de asimilar la infinita riqueza visual del objeto suprimiendo el conocimiento que de él tenemos. Recordemos que Kant, en la sección 16 de la Crítica del Juicio, también sintió una oposición entre la visión libre y el efecto limitante del pensamiento. Afirma que si al ver una configuración la relacionamos con un concepto, esto es, la reconocemos o fijamos conceptualmente, predominará el pensamiento sobre la visión empobreciendo así la contemplación del objeto.

Se sigue de lo anterior que definimos las imágenes visuales en contra de las conceptuales. Las primeras reproducen el aspecto visible de las cosas, lo que depende de nuestro punto de vista particular en el tiempo y el espacio; las segundas reproducen las cualidades que aunque no sean visibles sabemos que el objeto posee; éstas exigen nuestra participación para visualizar la imagen, aquéllas para entender el concepto detrás de la imagen; en una vemos al objeto en la configuración, en la otra vemos la configuración para pensar el objeto: en la primera decimos que vemos, en la segunda que interpretamos.

Las imágenes conceptuales facilitan la comunicación gracias a una estructura formal esquemática y regular (lo regular, para Kant, es lo que hace posible que percibamos un objeto como una entidad única e independiente a través de un concepto) que desalienta la atención hacia la imagen para centrarla en el mensaje que comunica. Las representaciones visuales, en cambio, necesitan mantener el interés en la apariencia formal de la imagen por medio de cualquier subterfugio que posponga la fijación conceptual. Es sólo una verdad a medias suponer que esta clase de representaciones depende de la complejidad, variedad e irregularidad de sus partes para atraer el escrutinio contemplativo; la otra mitad de la verdad sostiene que lo único que puede mantener un interés continuo en la apariencia visible de la imagen son las soluciones imaginativas, orginales y frescas que rompen con técnicas y procedimientos ya dosificados en una tradición y manejados por hábito. La oposición entre dos tipos distintos de imágenes se transforma así en un contraste entre dos maneras de proceder, dos diferentes tradiciones gráficas: una, estable y constante, cuyos valores nacen de la sencillez y la claridad, el orden y la simetría, como lo demuestra la continuidad y aparente ahistoricidad 
del ornamento;11 la otra, plena de reacciones y sacudidas, de revueltas y rechazos, pero también de innovaciones e inventos a una tradición en constante evolución técnica que comienza con Giotto, y de una conciencia histórica de su desarrollo presente desde la historia de la pintura de Giorgio Vasari.

Un último comentario que quiero hacer aquí es que el arte abstracto moderno parece compartir características de ambas tradiciones. Por un lado, ha preferido imágenes sencillas y bidimensionales de colores y líneas desligadas de una preocupación ilusionista, influido, entre otras cosas, por el arte primitivo de los espacios culturales periféricos. En su apariencia formal lo podriamos clasificar dentro de las imágenes conceptuales, pero debido a la actitud que exige como respuesta por parte del público, asi como por las preocupaciones que lo alimentan, forma parte de la tradición de imágenes visuales. La reacción hacia lo primitivo y el abandono de la sofisticada técnica de la pintura realista obedece a motivos francamente visuales. Aunque las formas de la pintura abtracta sean esquemáticas, la respuesta que piden es de contemplación visual; son el producto del rechazo de una figuración vuelta velo de oscuridad en lugar de ventana a la percepción.

11 E. H. Gombrich, El sentido del orden, Gustavo Gili, Barcelona. 